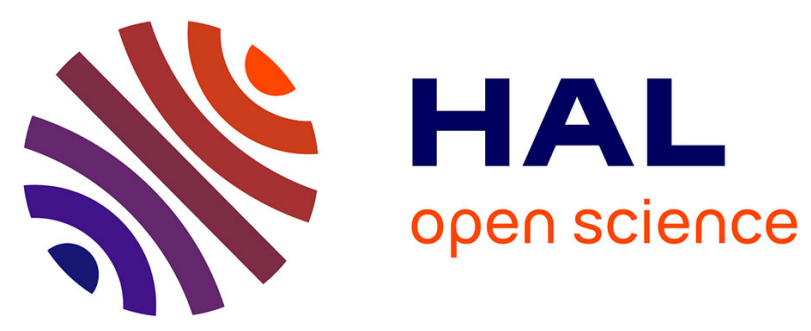

\title{
Differences in epidemiological features between ulcerative colitis and Crohn's disease: The early life-programmed versus late dysbiosis hypothesis
}

Laurent Beaugerie, Ebbe Langholz, Nynne Nyboe-Andersen, Benedicte

Pigneur, Harry Sokol

\section{To cite this version:}

Laurent Beaugerie, Ebbe Langholz, Nynne Nyboe-Andersen, Benedicte Pigneur, Harry Sokol. Differences in epidemiological features between ulcerative colitis and Crohn's disease: The early life-programmed versus late dysbiosis hypothesis. Medical Hypotheses, 2018, 115, pp.19-21. 10.1016/j.mehy.2018.03.009 . hal-01961997

\section{HAL Id: hal-01961997 \\ https: / hal.sorbonne-universite.fr/hal-01961997}

Submitted on 20 Dec 2018

HAL is a multi-disciplinary open access archive for the deposit and dissemination of scientific research documents, whether they are published or not. The documents may come from teaching and research institutions in France or abroad, or from public or private research centers.
L'archive ouverte pluridisciplinaire HAL, est destinée au dépôt et à la diffusion de documents scientifiques de niveau recherche, publiés ou non, émanant des établissements d'enseignement et de recherche français ou étrangers, des laboratoires publics ou privés. 


\title{
Differences in epidemiological features between ulcerative colitis and Crohn's disease: The early life-programmed versus late dysbiosis hypothesis
}

\author{
Laurent Beaugerie $^{\mathrm{a}, *}$, Ebbe Langholz ${ }^{\mathrm{b}}$, Nynne Nyboe-Andersen ${ }^{\mathrm{c}}$, Bénédicte Pigneur ${ }^{\mathrm{d}}$, \\ Harry Sokol ${ }^{\mathrm{a}}$, for the ECCO Epicom \\ ${ }^{a}$ Department of Gastroenterology, AP-HP, Hôpital Saint-Antoine F-75012 and UPMC Univ Paris 06, F-75005 Paris, France \\ ${ }^{\mathrm{b}}$ Gastroenheden D, Herlev and Gentofte Hospital, University of Copenhagen, Denmark \\ ${ }^{\mathrm{c}}$ Department of Gastroenterology, Zealand University Hospital, Køge, Denmark \\ d Department of Paediatric Gastroenterology, AP-HP, Hôpital Necker-Enfants Malades, Paris, BP, France
}

\begin{abstract}
A B S T R A C T
It is increasingly admitted that Crohn's disease and ulcerative colitis, the two entities of inflammatory bowel disease, are initiated and reactivated by environmental factors in genetically susceptible hosts, and result from aberrant immune response to specific intestinal microbes, in the context of altered composition of intestinal microbiota, called dysbiosis. We hypothesize that the role of the gut microbiota in Crohn's disease pathogenesis is linked to early-life abnormal crosstalk with the host immune system under construction. By contrast, in ulcerative colitis, the detrimental effect of intestinal dysbiosis could occur at any time of life, due to instant environment. This hypothesis could explain why the incidence of Crohn's disease raises many years later than that of ulcerative colitis in developing countries that adopt the Western lifestyle. This would also explain why many early-life events, such as caesarean section, increased hygiene and repeated antibiotic exposure, are risk factors for subsequent development of Crohn's disease, but not ulcerative colitis.
\end{abstract}

\section{Introduction}

Crohn's disease and ulcerative colitis, collectively referred to as inflammatory bowel disease (IBD), are lifelong gastrointestinal disorders that generally begin in adolescence or young childhood, even if clinical disease onset is possible at any age [1] The precise origin of IBD remains unknown, but it is increasingly accepted that both Crohn's disease and ulcerative colitis result from aberrant immune response to specific components of the intestinal microbiota in genetically susceptible hosts, with clinical flares of the diseases initiated and reactivated by environmental factors [2].

The intestinal microbiota is an ecological community of microorganisms (mainly bacteria, but also fungi and viruses) that colonize the human intestine from birth. The composition of this community is of increasing complexity from birth to early childhood, depending on evolving diet and other environmental factors, and becomes stable thereafter. This maturation process results from the constant interplay between environmental microorganisms, digested food, and eukaryotic intestinal epithelial and immune host cells. Of note, nature and function of immune host cells can be at least partially modulated by the host genome.
Intestinal microbiota dysbiosis, an impaired composition and/or functions of the intestinal microbiota, contributes at least partially to the pathogenesis of various diseases, including IBD. It is now established that adult patients with Crohn's disease or ulcerative colitis share common features of intestinal microbiota dysbiosis, consisting mainly of reduced diversity but also exhibit disease specific alterations, such as significant lack of the anti-inflammatory bacteria Faecalibacterium prausnitzii, and excess presence of some Proteobacteria in Crohn's disease [2]. Whether dysbiosis is a cause or a consequence of intestinal inflammation is an essential point. It is established that dysbiosis exist from diagnosis of IBD [3], and is more pronounced during inflammatory flares [2]. By contrast, it is not known whether dysbiosis precedes clinical onset of IBD in humans, but recent data in mice suggest that dysbiosis, favored by genetic predisposition and environmental factors, affects the host's immune response and thus amplifies dysbiosis in a vicious cycle that leads to intestinal inflammation [4].

Crohn's disease and ulcerative colitis are not two strictly distinct diseases. For instance, an individual can be diagnosed with a typical phenotype of ulcerative colitis and some years later develop a typical phenotype of Crohn's disease [1]. However, there are substantial

\footnotetext{
Abbreviations:IBD, inflammatory bowel disease

* Corresponding author at: Service de Gastroentérologie et Nutrition, Hôpital Saint-Antoine, 184 rue du faubourg Saint-Antoine, 75571 Paris Cedex 12, France.

E-mail address: laurent.beaugerie@aphp.fr (L. Beaugerie).
} 
differences between clinicopathological and epidemiological features of ulcerative colitis and Crohn's disease. For instance, intestinal lesions of ulcerative colitis are restricted to rectum and colon, and an active smoking status has an opposite effect on the course of the diseases.

One of the most intriguing epidemiological differences between the two subtypes of IBD is the fact that the initial rise in incidence of ulcerative colitis in a given country that acquires progressively the environment at risk for IBD (i.e., a western life style) precedes by several years the first rise in incidence of Crohn's disease [1,5].

This founding observation was the first step towards the elaboration of our hypothesis. How to explain that the same genes in the same environment do not reach the same expected consequences at the same time? We speculated that the response could come from a different constitution timing and impact of dysbiosis (the link between genes and environment) on disease onset between Crohn's disease and ulcerative colitis. We hypothesized that the role of the dysbiotic gut microbiota is distinct in Crohn's disease and ulcerative colitis pathogenesis. In Crohn's disease, it acts through early-life abnormal crosstalk with the host immune system under construction, whereas in ulcerative colitis it could play a role in disease onset later, at any time in life, due to the accidental combination of promoting factors, such as micro-organisms, diet, antibiotics, smoking cessation, pollution, etc

In a second step, in order to give consistency to our speculation, we explored whether the hypothesis fits with the main epidemiological known differences between Crohn's disease and ulcerative colitis.

\section{Delayed increase in incidence of Crohn's disease after societal westernization}

Initially regarded as disease of Caucasians in Western countries, IBD are now considered as related to common environmental exposures, irrespective of ethnicity, socio-economic status or geographical areas. The key risk factors are gathered under the term of westernization of society that includes urbanization, increased hygiene and low-fiber and high-meat diets.

These changes occurred first in UK, where the first case series of ulcerative colitis were reported at the beginning of the 20th century [7], and a progressive increase in the incidence of Crohn's disease from disease description in 1932 [8]. In China, the first cases of ulcerative colitis have been described in the immediate post Second World-war period, many years before the initial rise in the incidence of Crohn's disease [6]. In these countries and in many others, duration of the lag phase between the occurrence of ulcerative colitis and that of Crohn's disease is about ten years [1]. In agreement with our hypothesis, this time could correspond to the mean interval between early-life exposition to an altered gut microbiota and clinical onset of Crohn's disease in youngest patients. In the case of ulcerative colitis, acquired dysbiosis induced by environmental changes can rapidly lead to the clinical onset of the disease whatever the age of predisposed subjects.

\section{Incidence of Crohn's disease and ulcerative should be different between first and second-generation migrants from non- westernized to westernized countries}

According to our hypothesis, individuals who spent their childhood in non-westernized countries and migrated secondarily to westernized countries as first-generation migrants should not be at risk of Crohn's disease as they were not exposed to dysbiotic microbiota in early life. However they could immediately develop ulcerative colitis because of the instant environmental influence. The incidence of Crohn's disease and ulcerative colitis should not be different in second-generation migrants because of a common environment from early life. It is difficult to find data in the literature supporting this assumption as many IBD registries are of relatively recent date [9], and it is plausible that, in the last decades, people who lived in developing countries and then migrated to developed countries experienced at least partially a westernized way of life (urbanization, consumption of fast-food) before migrating. In the first papers on epidemiology of IBD coming from UK, the incidence of ulcerative colitis in first and second-generation Indian migrants was similar to that of native UK population and higher than in countries of origin [10]. In another paper, incidence of Crohn's disease in the same migrant population was lower than in native population [11], but not different between first and second-generation migrants. In recent population-based studies from Sweden and Canada, the authors did not find differences in Crohn's disease between first and second generation. However, in the Swedish study covering the 1964-2007 period, first-generation migrants from Africa, which is probably the less westernized continent, has a significantly lower standardized incidence ratio of Crohn's disease compared to the native population; this was not the case for ulcerative colitis [12].

\section{Early-life events that are believed to alter the development of} intestinal microbiota are at risk of subsequent Crohn's disease, not ulcerative colitis

Many early-life events are considered to potentially negatively impact the progressive constitution of intestinal microbiota during early childhood. Among others, caesarean section, high level of hygiene, and repeated antibiotic exposure. In general, these environmental risk factors present in early life that could alter the composition of intestinal microbiota, would have a greater impact on risk of Crohn's disease compared to ulcerative colitis, according to the hypothesis. We found concordant data in the literature illustrating this trend, which represents strong arguments supporting our hypothesis. A systematic literature review and meta-analysis demonstrated a significant association between caesarean delivery and the risk of developing Crohn's disease [13]. No association was found between caesarean delivery and ulcerative colitis [13]. The impact of domestic hygiene in infancy on the risk of development of Crohn's disease and ulcerative colitis was explored in a case-control study in UK. Compared to control population, markers of increased hygiene (hot-water tap, separate bathroom) were over-represented in patients who subsequently developed Crohn's disease, but not ulcerative colitis [14]. In a nationwide Danish cohort, the number of antibiotic courses during childhood was statistically correlated with the risk of developing Crohn's disease but not ulcerative colitis [15]. Of note, the strongest association was found between antibiotic use in the very early life ( $0-2$ months) and the subsequent development of Crohn's disease. In a meta-analysis including children and adults with IBD, exposure to antibiotics increased the risk of being newly diagnosed with Crohn's disease, but not ulcerative colitis [16].

\section{How to confirm our hypothesis?}

Further epidemiological arguments will become more and more difficult to obtain and interpret because of the progressive globalization of westernization of lifestyle. In the meanwhile, it would be helpful to develop prospective projects in the specific subgroups of adopted children and conjugal forms of IBD. Adopted children who spent their early life in the remaining non-westernized parts of the world should be more prone to develop ulcerative colitis than Crohn's disease according to our hypothesis. Similarly, couples who share IBD-predisposing environment and both develop IBD after marriage should be more often diagnosed with ulcerative colitis. Studies on intestinal microbiota and IBD-related dysbiosis are the most prone to shed light on the validity of the hypothesis. Increased use of feces biobanking for various purposes will make it possible to retrospectively look for pre-existing dysbiosis in patients who develop IBD. The best proof of hypothesis would come from projects such the Genetic, Environmental, and Microbial (GEM) project [17], in which unaffected individuals at high risk for IBD undergo a sequential assessment of environment, including microbiota. In individuals who eventually develop Crohn's disease, but not in those who develop ulcerative colitis, markers or predictors of intestinal 
dysbiosis should be detectable from early childhood.

\section{Author contributions}

LB raised the hypothesis. LB and HS jointly elaborated the points in the field of inflammatory bowel disease epidemiology and intestinal microbiota study that could support the hypothesis. The dysbiosis hypothesis project was discussed during regular meetings of the Epidemiological Committee (EpiCom) of the European Crohn's and Colitis Organisation (ECCO) from July 2016 to June 2017. EL and NNA reviewed jointly the hypothesis points related to epidemiology in the literature. BP and HS reviewed jointly the hypothesis points related to intestinal microbiota. LB was responsible for the writing of the first draft of the manuscript. All authors took part in the revision of the manuscript.

\section{Disclosure}

Laurent Beaugerie has received consulting fees from Janssen, Allergan and Pfizer, lecture fees from Abbvie, Janssen, MSD, Ferring Pharmaceuticals, Takeda and Tillots, and research support from Abbvie, Ferring Pharmaceuticals, Hospira-Pfizer, Janssen and Takeda. Ebbe Langholz has received lecture fees from Abbvie, Ferring Pharmaceuticals and MSD. Dr. Nyboe Andersen has received funding for travel and speakers fee from MSD and speakers fee from Ferring.Pharmaceuticals. Harry Sokol has received consulting fees from MSD, Danone, Takeda, Abbvie, Astellas, Enterome, Maat, Novartis, BMS, and research support from Biocodex. Bénédicte Pigneur discloses no conflicts.

\section{Funding}

This work was not supported by a dedicated funding.

\section{Acknowledgments}

Collaborators of the Epidemiological Committee (EpiCom) of the
European Crohn's and Colitis Organisation (ECCO) are Vito Annese, Naila Arebi and Marieke Pierik.

\section{References}

[1] Cosnes J, Gower-Rousseau C, Seksik P, et al. Epidemiology and natural history of inflammatory bowel diseases. Gastroenterology 2011;140:1785-94.

[2] Sartor RB, Wu GD. Roles for intestinal bacteria, viruses, and fungi in pathogenesis of inflammatory bowel diseases and therapeutic approaches. Gastroenterology 2017;152(327-339):e4.

[3] Gevers D, Kugathasan S, Denson LA, et al. The treatment-naive microbiome in newonset Crohn's disease. Cell Host Microbe 2014;15:382-92.

[4] Lamas B, Richard ML, Leducq V, et al. CARD9 impacts colitis by altering gut microbiota metabolism of tryptophan into aryl hydrocarbon receptor ligands. Nat Med 2016;22:598-605.

[5] Edouard A, Paillaud M, Merle S, et al. Incidence of inflammatory bowel disease in the French West Indies (1997-1999). Gastroenterol Clin Biol 2005:29:779-83.

[6] Kaplan GG, Ng SC. Understanding and preventing the global increase of inflammatory bowel disease. Gastroenterology 2017;152(313-321):e2.

[7] Allchin WH. A Discussion on "Ulcerative Colitis".: introductory address. Proc R Soc Med 1909;2:59-75.

[8] Srivastava ED, Mayberry JF, Morris TJ, et al. Incidence of ulcerative colitis in Cardiff over 20 years: 1968-87. Gut 1992;33:256-8.

[9] Benchimol EI, Mack DR, Guttmann A, et al. Inflammatory bowel disease in immigrants to Canada and their children: a population-based cohort study. Am J Gastroenterol 2015;110:553-63.

[10] Probert CS, Jayanthi V, Pinder D, et al. Epidemiological study of ulcerative proctocolitis in Indian migrants and the indigenous population of Leicestershire. Gut 1992;33:687-93.

[11] Jayanthi V, Probert CS, Pinder D, et al. Epidemiology of Crohn's disease in Indian migrants and the indigenous population in Leicestershire. Q J Med 1992;82:125-38.

[12] Li X, Sundquist J, Hemminki K, et al. Risk of inflammatory bowel disease in firstand second-generation immigrants in Sweden: a nationwide follow-up study. Inflamm Bowel Dis 2011;17:1784-91.

[13] Li Y, Tian Y, Zhu W, et al. Cesarean delivery and risk of inflammatory bowel disease: a systematic review and meta-analysis. Scand J Gastroenterol 2014;49:834-44.

[14] Gent AE, Hellier MD, Grace RH, et al. Inflammatory bowel disease and domestic hygiene in infancy. Lancet 1994;343:766-7.

[15] Hviid A, Svanström H, Frisch M. Antibiotic use and inflammatory bowel diseases in childhood. Gut 2011;60:49-54.

[16] Ungaro R, Bernstein CN, Gearry R, et al. Antibiotics associated with increased risk of new-onset Crohn's disease but not ulcerative colitis: a meta-analysis. Am J Gastroenterol 2014;109:1728-38.

[17] Kevans D, Silverberg MS, Borowski K, et al. IBD genetic risk profile in healthy firstdegree relatives of Crohn's disease patients. J Crohns Colitis 2016;10:209-15. 